\title{
1 Magnetic immunochromatographic test for histamine detection in wine
}

2 Amanda Moyano ${ }^{1-2}$, María Salvador ${ }^{2,5}$, José C. Martínez-García ${ }^{2}$, Vlad Socoliuc ${ }^{4}$, Ladislau Vékás ${ }^{4}$, Davi-

3 de Peddis ${ }^{5}$, Miguel A. Alvarez ${ }^{3}$, María Fernández ${ }^{3}$, Montserrat Rivas ${ }^{2 *}$, M. Carmen Blanco-López ${ }^{1^{*}}$

4

$5{ }^{1}$ Department of Physical and Analytical Chemistry, University of Oviedo, 33006 Oviedo, Spain

$6{ }^{2}$ Department of Physics, University of Oviedo, 33204 Gijón, Spain

7 릴 Research Institute of Asturias, IPLA (CSIC), Villaviciosa, Asturias, Spain

$8{ }^{4}$ Laboratory of Magnetic Fluids, Center for Fundamental and Advanced Technical Research, Romanian

9 Academy - Timisoara Branch, 300223 Timisoara, Romania

$10{ }^{5}$ Institute of Structure of Matter (CNR), 00015 Monterotondo Scalo (RM), Italy

$11 *$ Corresponding authors: rivas@uniovi.es; cblanco@ uniovi.es 
13 Histamine, a biogenic amine, is abundant in fermented foods and beverages, notably wine. A high in-

14 take of this monoamine may produce adverse reactions in humans, which may be severe in individuals

15 with a reduced capacity to catabolize extrinsic histamine. Thus, control of histamine concentration during

16 wine production and before distribution is advisable. Simple, rapid, point-of-use bioanalytical platforms

17 are needed because traditional methods for the detection and quantification of histamine are expensive

18 and time-consuming. This work applies the lateral flow immunoassay technique to histamine detection.

19 Superparamagnetic particle labels, and an inductive sensor designed to read the test line in the immunoas-

20 say, enable magnetic quantification of the molecule. The system is calibrated with histamine standards in

21 the interval of interest for wine production. A commercial optical strip reader is used for comparison

22 measurements. The lateral flow system has a limit of detection of 1.2 and $1.5 \mathrm{mg} / \mathrm{L}$ for the inductive and

23 optical readers, respectively. The capability of the inductive system for histamine quantification is

24 demonstrated for wine samples at different processing points (at the end of alcoholic fermentation, at the

25 end of malolactic fermentation, in freshly bottled wine, and in reserve wine). The results are validated by

26 ultra-high-performance liquid chromatography.

27 Keywords: biogenic amines; histamine; lateral flow immunoassay; superparamagnetic nanoparticles;

28 histamine biosensor. 
 \\ 1. Introduction}

Biogenic amines (BAs) are basic nitrogenous compounds with low molecular weight and biological activity. The most frequent among them are histamine, tyramine, tryptamine, putrescine and cadaverine, and are present in several foodstuffs in a variable range of concentrations depending on the food (1). BAs are produced by certain bacteria and yeasts during the fermentation of wines, and other beverages and foods as beer, chocolate or cheese. They can also be produced by the normal metabolic activity of animal and vegetal cells. However, in fermented products, where BAs can reach the highest concentrations, they are normally generated by the microbial decarboxylation of the corresponding amino acids. In some cases, these microorganisms, Gram-positive and Gram-negative bacteria, are part of the starter and/or the secondary microbiota, necessary to produce the desired fermentation of the product. In other cases they are present as food contaminants (2).

Histamine is one of the most abundant and toxic BAs in fermented foods. Even in small amounts it can produce symptoms in susceptible individuals, and in high levels it can cause serious toxicological problems (3). In alcoholic beverages, the toxic effects can be stronger due to the inhibition effect of alcohol on the intestinal epithelium detoxification system (4), which is one of the main reasons why it is so important to analyse wines.

Despite the risk of histamine, there is no consensus in the legislation to regulate its concentration in food. Only in fishery products the maximum histamine levels have been set at $50 \mathrm{mg} / \mathrm{kg}$ by the USA Food and Drug Administration (5) and at $100 \mathrm{mg} / \mathrm{kg}$ by the European Community (6). In the case of wine, there are no legal restrictions, but some European countries recommend upper limits that range from 2 to $10 \mathrm{mg} / \mathrm{L}$ depending on the country (7-9). These considerations need to be taken into account to facilitate commercial transactions.

But, besides the health risks of BAs, they can also affect the organoleptic quality of the wine. It has been reported that histamine can be generated during different stages of the winemaking process: alcoholic fermentation by yeasts $(10,11)$, malolactic fermentation by bacteria $(12,13)$ and ageing $(14)$. Other factors such as time, storage conditions (temperature and $\mathrm{pH}$ ), raw material quality and the possibility of contamination during aging can contribute to increase histamine content. All kind of wines may contain BAs, but typically red wines have more than other varieties (white, rose, rice and Porto) due to their vinification processes (15), and even high-rated wines may have them.

58 These considerations have prompted attentive wine producers and consumers to get interested in bio59 analytical methods that are fast and unsophisticated to detect and quantify BAs for sensitive individuals and wine producers both during the winery process and in the final product.

61 Up to now, different methods have been reported to detect BAs. Currently, the most used analytical 62 technique is Liquid Chromatography (LC) coupled to ultraviolet, fluorescence or mass spectrophotometry detectors (16). Gas Chromatography (GC) is a faster alternative for which pre-derivatization is required to increase the volatility and decrease polarities of the BAs (17). Capillary Electrophoresis (CE) is the second most common technique for BAs determination because is very adequate for screenings (18). The chromatographical techniques described above (LC, GC and CE) give a precise and sensitive analysis of numerous BAs simultaneously. However, they are time consuming, require expensive instruments and qualified personnel. Non-chromatographic analyses are alternatives that include biosensors (19-21), En-

69 zyme Linked Immunosorbent assay (ELISA) (22), and flow-injection analysis (23). These methods are 70 faster but require sample pre-treatment to clean up matrix interferences. Moreover, they still require spe- 
cialized personnel and are difficult to implement in a cellar, where a rapid respond with the minimum complexity is needed.

Lateral Flow Immunoassay (LFIA) is a powerful point-of-use system for simple, rapid, portable and low-cost analysis in different fields (clinical diagnosis, food safety and environment). The LFIA technique is based on an immunochromatografic separation at nitrocellulose dipsticks, as sample flows by capillary action. The test involves different cellulosic materials (sample pad, conjugate pad, nitrocellulose membrane and adsorption pad) assembled on a plastic backing to get robustness. The recognition of the analyte relies on the use of specific molecules immobilized on the membrane in two lines (test and control lines). LFIA combines the technology of ELISA and chromatography, overcoming some drawbacks of both methods, such as time-consumption and complexity. There are different formats depending on the analyte. The most common are: sandwich format, in which two antibodies are used to recognize the analyte, and competitive format for low molecular weight compounds, such as histamine, in which a single antibody is available for the recognition of the molecule of interest. Several systems have been used as reporter labels in LFIAs: gold, iron oxide, carbon, selenium or silver nanoparticles (NPs), coloured latex beads, quantum dots, enzymes or liposomes. Frequently, LFIA operates on a purely qualitative basis, displaying a positive/negative answer. Motivated by the concern on fishery products, lateral flow devices for a rapid visual detection of histamine have been developed (24), some of which can be applied also to wine. These tests are aimed at detecting unsafe levels of histamine according to legal regulation on fish, so they provide a positive/negative response with a threshold of $50 \mathrm{ppm}$ or $200 \mathrm{ppm}$.

This article focuses on adding quantitative capacities to LFIAs for histamine in red wine, while reducing the LOD to levels to match the European recommendations for this product (2-10 ppm). Associating the LFIA to a reading equipment which does not compromise the rapidity and simplicity of the test is major challenge (25). Recently, magnetic nanoparticles have been proposed as LFIA labels to enable, besides the visual detection, magnetic quantification (26-29). The authors have reported on a novel inductive sensor to quantify superparamagnetic particles without the application of exciting fields, which largely reduces the complexity and cost of the device $(30,31)$. The system, adapted for LFIA strips has been successfully used to determine prostate specific antigen concentrations in the clinical range of interest by using a sandwich format (32). This measuring device does not require bulky components. This means that it can be easily miniaturised to a point-of-use portable device.

100 In this article we use this novel approach to detect and quantify histamine, in the concentration range of interest for wines. Although the thresholds already adopted as recommendation in some EU countries are $2-10 \mathrm{mg} / \mathrm{L}$, studies on 100 selected high-quality red wines made from seven different cultivars found that $34 \%$ were above this limit and as high as $27 \mathrm{mg} / \mathrm{L}(9)$. The range of interest widens then to $1-100$ $\mathrm{mg} / \mathrm{L}$.

105 We report for the first time on a histamine quantification technique for red wine based on a magnetic 106 competitive LFIA. Red wine is especially challenging to its intensely coloured matrix, that implies high 107 background and poor reliability for the traditional optical readers. The purple colour of red wine aggra108 vates the problem as the classical labels are gold NPs that yield a similar red-purple colour. Therefore, this work was aimed at developing a LFIA based on superparamagnetic labels. The immunoassay is combined to an inductive sensor capable to quantify the magnetic moment of such labels. The system has been tested with red wine samples and validated against Ultra High-Performance Liquid Chromatography (UHPLC) analyses. The system proved to be successful as histamine point-of-use analytical technique in the range of regulatory concern. 


\section{Materials and methods}

\subsection{Reagents and instruments for the immunoassay}

Mouse histamine monoclonal antibody (MBS2025715) and histamine-BSA conjugate antigen (MBS358205) were purchased from Mybiosource. Anti-mouse IgG, Bovine Serum Albumin (BSA), 1ethyl-3-[3-dimethylaminopropyl]-carbodiimide hydrochloride (EDC), N-hydroxysuccinimide (NHS), 2(N-Morpholino)ethanesulfonic acid (MES) and histamine dihydrochloride were provided by SigmaAldrich (Spain). Recombinant protein A/G was purchased at Thermo-Scientific (Massachusetts, USA). Gold nanoparticles of size $40 \mathrm{~nm}$ were purchased from BB International (UK). Disposable $0.45 \mu \mathrm{m}$ PVDF filters were purchased from GE Healthcare Life Sciences.

Glass fibre membrane (GFCP001000) used as sample pad and backing cards (HF000MC100) were purchased from Millipore (Germany). Other materials used were nitrocellulose membranes (UniSart CN95, Sartorius, Spain) and absorbent pads (Whatman, USA). Based on previous results, the sample buffer consisted of $10 \mathrm{mM}$ Phosphate-Buffer (PB) $\mathrm{pH} 7.4$ with $0.5 \%$ Tween-20 and 1\% BSA.

An IsoFlow reagent dispensing system (Imagene Technology, USA) was used to dispense the detection lines (dispense rate $0.100 \mu \mathrm{L} / \mathrm{mm}$ ) and the strips were cut with a guillotine Fellowes Gamma (Spain). A portable strip reader ESE Quant LR3 lateral flow system (Qiagen Inc., Germany) was used to quantify the intensity of the test line by reflectance measurements.

\subsection{Functionalization of labels with protein $\mathrm{A} / \mathrm{G}$}

Protein A/G was conjugated to gold nanoparticles for its functionalization. A gold colloidal titration was carried out to find the optimal concentration of protein $\mathrm{A} / \mathrm{G}$ to stabilize the gold nanoparticles. The titration experiments show that $1.5 \mathrm{mg} / \mathrm{mL}$ of protein is the optimal concentration for its functionalization. For the conjugation, $100 \mu \mathrm{L}$ of $1.5 \mathrm{mg} / \mathrm{mL}$ protein $\mathrm{A} / \mathrm{G}$ was added to $1.5 \mathrm{~mL}$ of gold nanoparticles in suspension. After shaking for $1 \mathrm{~h}, 100 \mu \mathrm{L}$ of blocking solution ( $1 \mathrm{mg} / \mathrm{mL}$ BSA in PB $10 \mathrm{mM}, \mathrm{pH}$ 7.4) was added to block the residual surfaces of the gold conjugate. After 20 min of blocking reaction, the mixture was centrifuged at $6,800 \mathrm{~g}$ for $20 \mathrm{~min}$. The supernatant was discarded, and the pellet was resuspended in $2 \mathrm{mM}$ of PB buffer, $\mathrm{pH} 7.4$, with $10 \%$ sucrose and $1 \%$ BSA. The conjugates protein A/G-gold nanoparticles were stored at $4{ }^{\circ} \mathrm{C}$ until used.

Superparamagnetic magnetite nanoparticles prepared by a coprecipitation route and coated with a double layer of oleic acid (33) were functionalized using recombinant protein A/G to develop the immunoassay. Firstly, the carboxyl groups of the nanoparticles were activated using the carbodiimide chemistry. For this, $100 \mu \mathrm{L}$ of EDC ( $5 \mathrm{mg} / \mathrm{mL}$ in MES $50 \mathrm{mM}, \mathrm{pH} 6.00), 100 \mu \mathrm{L}$ of NHS $(5 \mathrm{mg} / \mathrm{mL}$ in MES $50 \mathrm{mM}, \mathrm{pH} 6.00$ ) and $100 \mu \mathrm{L}$ of recombinant protein $\mathrm{A} / \mathrm{G}$ (different concentrations were used to optimize the assay) were mixed with $10 \mu \mathrm{L}$ of nanoparticles. After shaking for $4 \mathrm{~h}$, the residual carboxyl groups on

147 the surfaces were blocked by adding $100 \mu \mathrm{L}$ of the blocking solution (1\% BSA in PB $10 \mathrm{mM}, \mathrm{pH}$ 7.4).

148 Then, the mixture was centrifuged at $21,448 \mathrm{~g}$ for $20 \mathrm{~min}$. Finally, $300 \mu \mathrm{L}$ of supernatant was discarded and the pellet was resuspended in PB $10 \mathrm{mM}, \mathrm{pH}$ 7.4.

\subsection{Characterization of nanoparticles conjugates by Dynamic Light Scattering} vern Instruments, Malvern, UK) equipped with a solid-state He-Ne laser $(633 \mathrm{~nm})$. This instrument was 
used to monitor the conjugation process. A total of three readings were carried out at $25{ }^{\circ} \mathrm{C}$. Each reading was composed of 15 measurements of the backscattered $\left(173^{\circ}\right)$ intensity. Zetasizer software version 7.03 was used for data processing and analysis.

\subsection{Preparation of the immuno-strips}

The competitive LFIA to detect histamine was carried out in a dipstick format. The nitrocellulose membrane ( $25 \mathrm{~mm}$-wide) was incorporated into a backing plastic card to make it robust enough. Two lines of antibodies were immobilised across the nitrocellulose strip: (i) the test line to provide the result of the analysis, and (ii) the control line to get the guarantee that the liquid sample has flowed adequately along the strip. Both lines were applied by the IsoFlow dispenser at a rate of $0.100 \mu \mathrm{L} / \mathrm{mm}$. A $1 \mathrm{mg} / \mathrm{mL}$ concentration of histamine-BSA conjugate was used for the test line and a $1 \mathrm{mg} / \mathrm{mL}$ concentration of anti IgG for the control line. The nitrocellulose membrane was dried for $20 \mathrm{~min}$ at $37{ }^{\circ} \mathrm{C}$ after the immobilization of the control and test lines. Then, the sample pad and the absorbent pad were settled onto a backing card with an overlap between them of $2 \mathrm{~mm}$. The complete strip was cut into individual $5 \mathrm{~mm}$ wide dipsticks.

\subsection{Magnetic quantification}

To provide a quantitative signal of the test line an inductive sensor specially developed for strip immunoassays was used (32). Its sensing head consists of a double copper line printed on a rigid insulating substrate across which alternating current flows. The magnitude and phase of the sensing head impedance are continuously monitored by a precision impedance analyser (Agilent 4294A) using 16048G test leads and $500 \mathrm{mV} / 20 \mathrm{MHz}$ excitation voltage. The change of magnetic permeability produced by the particles in the surrounding of the conductor increases significantly its impedance. The test lines on the strips were scanned laterally over the sensing head by a micro-positioner, producing a peak of the impedance signal over the base line that is integrated to account for all the particles in the line no matter how they are distributed. The signal provided by the sensor is then measured in $\Omega \cdot \mathrm{mm}$ coming from the cumulative integral of the impedance $(\Omega)$ across the width of the test line $(\mathrm{mm})$. This alteration in the impedance is directly proportional to the number of superparamagnetic nanoparticles at the test line. As the magnetic NPs were used in the strips as labels, this approach was used to calibrate the quantification of histamine. After the calibration with histamine standards, a similar procedure was used to quantify the concentration of histamine in real red wine samples.

\subsection{Optical measurements}

A portable strip reader ESE-Quant LR3 lateral flow system (Qiagen Inc., Germany) was used to quantify the colour intensity of the test line by reflectance measurements. The optical reader analyses the reflectance at the control and test line by using two channels (LED excitation and photodiode detection). The reader scans the strip by illuminating it with a light beam and then measures the attenuation from the surface of the strip through a confocal detector. The detector registers the signal and converts it into an electrical signal that is related to the amount of analyte at the control and test lines. The device provides values in units of $\mathrm{mm} \cdot \mathrm{mV}$, resulting from integrating the electrical signal $(\mathrm{mV})$ across the width of the test line $(\mathrm{mm})$. 
1912.7 Validation by Ultra High-Performance Liquid Chromatography (UHPLC) measurements

193 The wine samples were prepared and analysed by UHPLC following a method reported elsewhere 194 (34). The samples analysed correspond to red wine from different elaboration stages, at the end of the 195 alcoholic fermentation (sample A), freshly bottled (sample B), reserve wine (sample C) and at the end of 196 the malolactic fermentation (samples D and E), all from the Vino de Cangas Protected Origin Region 197 (from Asturias in Spain).

\section{3. Results and discussion}

\subsection{Optimization of the immunoassay}

The first step to develop the immunoassay was to optimize the amount of protein used to coat the nanoparticles and the concentration of antibody.

\section{3.1.1 Protein A/G concentration for nanoparticles conjugation}

203 Different concentrations of recombinant protein A/G were tested (1,2 and $3 \mathrm{mg} / \mathrm{mL})$. Dynamic Light 204 Scattering (DLS) measurements were carried out to confirm the conjugation reaction. This technique 205 allows comparison between nanoparticles hydrodynamic size before and after the conjugation reaction. 206 The hydrodynamic diameter of nanoparticles before conjugation was $86.6 \mathrm{~nm}$ (PDI 0.2). The $\zeta$-average of 207 the hydrodynamic sizes were $479.8 \mathrm{~nm}$ (PDI 0.4), $193.0 \mathrm{~nm}$ (PDI 0.4) and $120.8 \mathrm{~nm}$ (PDI 0.3) after con208 jugation with $1 \mathrm{mg} / \mathrm{mL}, 2 \mathrm{mg} / \mathrm{mL}$ and $3 \mathrm{mg} / \mathrm{mL}$ of protein, respectively (Figure 1). The results showed 209 that, for all concentrations of protein A/G, the nanoparticles size increased after the addition of the pro210 tein. This demonstrates that the conjugation process through the carbodiimide chemistry was successful.

211 Furthermore, the diameter of the conjugates was larger when concentration of the protein was lower. This 212 could be explained because a protein molecule could bind to several nanoparticles when there were not 213 enough molecules to cover every single nanoparticle, thus aggregates were formed.

Insert Figure 1

Figure 1 Hydrodynamic size distribution profiles of superparamagnetic iron oxide nanoparticles before (solid black line) and after conjugation with concentrations of $1 \mathrm{mg} / \mathrm{mL}$ (red), $2 \mathrm{mg} / \mathrm{mL}$ (blue) and $3 \mathrm{mg} / \mathrm{mL}$ (dashed) of protein $\mathrm{A} / \mathrm{G}$.

218 With the aim to select the most suitable protein concentration, the immunoassay without histamine 219 (blank sample) was carried out in the range $1-3 \mathrm{mg} / \mathrm{mL}$ and the line tests were analysed by reflectance 220 measurements using reader ESE-Quant LR3 lateral flow system. In all cases, the aggregates were able to 221 flow through the nitrocellulose membrane by capillarity. The results of the measurements of the test line 222 yielded values of $909.99,845.73$ and $639.40 \mathrm{~mm} \cdot \mathrm{mV}$ for $1 \mathrm{mg} / \mathrm{mL}, 2 \mathrm{mg} / \mathrm{mL}$ and $3 \mathrm{mg} / \mathrm{mL}$ of protein, 223 respectively. The reflectance signal increases when the diameter of protein A/G-NP conjugates is larger 224 because in this case there are more NPs attached to each antibody unit. These agglomerates have a signal 225 amplification effect, proportional to the size of the conjugate. In view of these results we concluded that $2261 \mathrm{mg} / \mathrm{mL}$ of recombinant protein A/G produced the largest signal. Therefore, this was the concentration 227 chosen for the next experiments. 
229 Different concentrations of antibody were assayed in order to optimise the signal. This step was made 230 with gold conjugates and used to estimate the antibody concentration for the competitive assay. The anti231 body was added during the first step of the immunoassay and therefore, direct binding to the histamine232 BSA complex immobilized on the membrane occurs. For the immunoassays $13,10,9$ and $5 \mathrm{mg} / \mathrm{L}$ of 233 antibody were used. The reflectance measurements yielded 996.97, 984.62, 862.05 and $431.48 \mathrm{~mm} \cdot \mathrm{mV}$, 234 respectively. Finally, $10 \mathrm{mg} / \mathrm{L}$ was chosen because, even when the signal increases with the concentration, there were not significant differences between 10 and $13 \mathrm{mg} / \mathrm{L}$.

\subsection{Competitive lateral flow immunoassay procedure}

237 The test to quantify histamine is based on a competitive immunoassay, thus the relationship between 238 the concentration and signals, either magnetic or optical, tends asymptotically to zero. The procedure 239 consists of two steps, as illustrated in ¡Error! No se encuentra el origen de la referencia.. The first step 240 is the competition of the anti-histamine antibodies in solution for the histamine in the sample and the one 241 immobilized at the test line. The second step is the colour developing, based on the retention of the conjugate protein A/G-NP at the test line thanks to the ability of protein $\mathrm{A} / \mathrm{G}$ to bind to antibodies of any

243 kind. The surplus of protein A/G-NP (not retained at the test line) proceed along the strip and are trapped

244 at the control line by the Fc region of the anti-IgG and anti-histamine antibodies (see Figure 2).

245 In order to calibrate the strips, several histamine standard solutions were prepared in $10 \mathrm{mM}$ PB and $246 \mathrm{pH}$ 7.4. The competitive LFIA was carried out in dipstick format. For the first step, $10 \mu \mathrm{L}$ of histamine of 247 different concentrations and $2 \mu \mathrm{L}$ of anti-histamine antibody $(0.5 \mathrm{mg} / \mathrm{mL})$ were transferred into a micro248 tube from a stock solution to get a final concentration of the anti-histamine antibody of $10 \mathrm{mg} / \mathrm{L}$. Then 249 buffer was added always keeping a final volume of $100 \mu \mathrm{L}$ ( $98 \mu \mathrm{L}$ of buffer for the blank and $88 \mu \mathrm{L}$ of 250 buffer for the samples). The optimized running buffer had 1\% BSA. The sample pad was introduced into 251 the mixture and the solution flowed along the strip by capillary action. After $30 \mathrm{~min}, 10 \mu \mathrm{L}$ of NPs coated 252 with protein $\mathrm{A} / \mathrm{G}$ and $90 \mu \mathrm{L}$ of running buffer were added to the microtube for the developing step. Insert Figure 2

Figure 2 Schematic illustration of the competitive LFIA. (A) First step: immobilization of the antihistamine antibodies. (B) Second step: colour development.

\subsection{Histamine standards calibration}

257 To calibrate the strips, several histamine standard solutions were prepared by dilution and assayed 258 following the procedure previously described. In a first run the experiments were conducted in a wide 259 range of histamine concentrations. The protein concentration in the functionalization protocol was 1.5 and $2602 \mathrm{mg} / \mathrm{mL}$ for gold and magnetic nanoparticles respectively. Figure 3 shows the calibration curves in the 261 immunoassays using gold (red) and iron oxide (black) NPs as labels. Six standard samples with histamine 262 concentrations in the range from $10^{-3}$ to $10^{2} \mathrm{mg} / \mathrm{L}$, besides a negative reference sample, were run by trip263 licate and measured with the optical reader. The results yield sigmoid-shape profiles, characteristic of 264 competitive immunoassays. For very low concentrations, the curve has an asymptotic behaviour as a 265 result of the total occupancy of the immobilized histamine-BSA complexes by anti-histamine antibodies. 266 The measured points have been fitted in Figure 3 (dotted lines) using the four-parameter logistic equation: 


$$
S=\frac{\alpha-\delta}{1+(C / \gamma)^{\beta}}+\delta
$$

\section{5}

where $S$ and $C$ are the sensor measurement and the histamine concentration, $\alpha$ and $\delta$ are the $S$-values of the upper and lower asymptote, respectively, $\beta$ is the slope at the inflection point, and $\gamma$ is the value of $C$ corresponding to $50 \%$ of the maximum asymptote (35). The parameters values used for the fits of Figure 3 were respectively $\alpha=1110 \mathrm{~mm} \cdot \mathrm{mV}, \beta=0.8, \gamma=5.3 \mathrm{mg} / \mathrm{L}$ and $\delta=160 \mathrm{~mm} \cdot \mathrm{mV}$ (red line) and $\alpha=1130 \mathrm{~mm} \cdot \mathrm{mV}, \beta=0.8, \gamma=4.5 \mathrm{mg} / \mathrm{L}$ and $\delta=190 \mathrm{~mm} \cdot \mathrm{mV}$ (black line). This first analysis leads to the conclusion that quantification is feasible in the range of $1-100 \mathrm{mg} / \mathrm{L}$ for the gold nanoparticles and 0.1-100 mg/L for the iron oxide superparamagnetic particles. Besides their wider working range, iron oxide NPs have the advantage of enabling the magnetic pre-concentration of the analyte. Although this procedure has not been yet tested in histamine immunoassays, it has been commonly used for preconcentration of analytes associated to different bioanalytical techniques (36). This allows bringing the samples with lower concentrations into the working range by a simple magnetic pre-treatment.

\section{Insert Figure 3}

Figure 3 Quantification of LFIAs by the optical reader using gold (red) and iron oxide (black) NPs. The lines plotted to guide the eye are four-parameter sigmoid curves. Inset: One of the series of standard samples used to obtain the red curve, with the control line on top and the test line below.

Figure 4 shows a detailed calibration with magnetic NPs in the range $1-100 \mathrm{mg} / \mathrm{L}$. For this, the A/G protein concentration for functionalization was optimized according to the DLS results. Optical and inductive readers have been used, the latter yielding better correlation factor. Dotted lines represent the least-squares linear fit of the data; slopes, $y$-intercepts and correlation factors are also shown on the graph. The limits of detection (LOD) have been calculated following ref. (37) from the blank-subtracted results and gives values of $1.2 \mathrm{mg} / \mathrm{L}$ and $1.5 \mathrm{mg} / \mathrm{L}$ for the inductive and optical methods, respectively.

\section{Insert Figure 4}

Figure 4 Inductive (left axis) and optical (right axis) signals of the magnetic LFIA as a function of the concentration of histamine. Least-squares linear regression curves are plotted as dotted lines. Inset: One of the series of standard samples used to obtain the plotted lines. The control line is on top and the test line below.

\subsection{Application to wine samples}

The analytical method was tested against five samples of red wine taken at different stages of the fabrication. The only pre-treatment was a simple filtering through a $0.45 \mu \mathrm{m}$ PVDF filter. All the assays were performed in triplicate. The strips were measured with the inductive reader once dried, to get a quantitative reproducible reading.

Initial tests were done with both type of particles, iron oxide and the traditional colloidal gold. For comparison, Figure 5 shows an image of both types of strips after running a sample of red wine. Even a naked eye inspection allows concluding that red wine stains the white paper. This is especially remarkable in the case of gold labels which seem not to flow as well as magnetite. In such case, a quantitative determination by optical measurements becomes impossible or is very poor. For this reason, together with 
the better results yielded by the calibration, the combination of iron oxide NPs and inductive sensor was chosen to perform the histamine quantification. The results are summarized in Table 1.

\section{Insert Figure 5}

Figure 5 LFIAs run with red wine samples using (A) superparamagnetic nanoparticles and (B) colloidal gold as reporters.

To validate the results, wines were also analysed by UHPLC and the results of histamine content are compared in Table 1. The error in the UHPLC measurements comes from the injection volume, which has been considered the only significant source of error. In the case of the LFIA, several error sources were identified that influence the inductive signal value: the printing of the antibody across the membrane (which may have small inhomogeneities in the line width), the guillotine cut of the strip from the membrane original card (this produces variability in the width of the strips), and the sensor resolution. Considering that the errors produced are probabilistically independent, we can use the rule of error propagation to add up the relative errors. For this calculation three strips have been run with each wine and each of them has been measured four times. The resulting uncertainty of the sensor signals for the different wines is in the range $2-18 \%$ for the optical measurement and $2-5 \%$ for the inductive sensor. The uncertainties of the concentrations shown in Table 1 have been obtained by the propagation rule applied to the calibration curve considering the errors of the slope and $y$-intercept given in Figure 4.

The LFIA values of the histamine content measured with the commercial optical reader are deficient. Moreover, the relative uncertainties are unacceptable due mainly to a considerable variability in the three strips of each wine. The problem is associated to the variability in colour intensity of the three strips of each wine more than a lack of sensitivity of the reader itself. For this method to be useful for quantification, the removal of the interfering matrix would be necessary. In contrast, the LFIA histamine levels given by the inductive reader are remarkably similar to the reference, taking into account the margins of error. Only wines D and $\mathrm{E}$ fall out of these ranges, the average LFIA value being overestimated in about a $30 \%$.

To investigate the possible origin of this deviation, several BAs have been quantified by UHPLC in the wines under study, namely, histamine, putrescine, cadaverine, tyramine, phenylethylamine and tryptamine (see Table 2).

Table 1 Results obtained by magnetic LFIA coupled to the inductive sensor and UHPLC for the red wine samples analysed in this work.

\begin{tabular}{|c|c|c|c|c|c|c|c|}
\hline \multirow{2}{*}{$\begin{array}{c}\text { Wine } \\
\text { A }\end{array}$} & \multirow{2}{*}{$\begin{array}{l}\text { Stage of fabrication } \\
\begin{array}{c}\text { End of the alcoholic } \\
\text { fermentation }\end{array}\end{array}$} & \multicolumn{2}{|c|}{$\begin{array}{l}\text { LFIA \& inductive } \\
\text { sensor } \\
\mathrm{mg} / \mathrm{L} \quad \mid \mathrm{mM}\end{array}$} & \multicolumn{2}{|c|}{$\begin{array}{l}\text { LFIA \& optical sensor } \\
\text { mg/L | mM }\end{array}$} & \multicolumn{2}{|c|}{$\begin{array}{l}\text { UHPLC } \\
\mathrm{mg} / \mathrm{L} \mid \mathrm{mM}\end{array}$} \\
\hline & & $46 \pm 2$ & $0.41 \pm 0.02$ & $25 \pm 3$ & $0.22 \pm 0.03$ & $44 \pm 3$ & $0.39 \pm 0.03$ \\
\hline $\mathrm{B}$ & Freshly bottled & $82 \pm 4$ & $0.74 \pm 0.04$ & $56 \pm 14$ & $0.50 \pm 0.13$ & $83 \pm 3$ & $0.74 \pm 0.03$ \\
\hline $\mathrm{C}$ & Reserve wine & $25 \pm 3$ & $0.22 \pm 0.03$ & $10 \pm 1$ & $0.09 \pm 0.01$ & $20 \pm 3$ & $0.18 \pm 0.03$ \\
\hline $\mathrm{D}$ & $\begin{array}{l}\text { End of the malolactic } \\
\text { fermentation }\end{array}$ & $63 \pm 4$ & $0.57 \pm 0.04$ & $37 \pm 7$ & $0.33 \pm 0.06$ & $46 \pm 3$ & $0.42 \pm 0.03$ \\
\hline $\mathrm{E}$ & $\begin{array}{l}\text { End of the malolactic } \\
\text { fermentation }\end{array}$ & $65 \pm 5$ & $0.58 \pm 0.05$ & $101 \pm 18$ & $0.90 \pm 0.16$ & $55 \pm 3$ & $0.49 \pm 0.03$ \\
\hline
\end{tabular}


Table 2 Concentrations of biogenic amines by UHPLC. All the samples are red wine at different steps of the fabrication.

\begin{tabular}{|c|c|c|c|c|c|c|}
\hline $\begin{array}{l}\text { Biogenic } \\
\text { amines }\end{array}$ & Structure & $\begin{array}{l}\text { Wine A } \\
(\mathrm{mM})\end{array}$ & $\begin{array}{l}\text { Wine B } \\
(\mathrm{mM})\end{array}$ & $\begin{array}{l}\text { Wine C } \\
(\mathrm{mM})\end{array}$ & $\begin{array}{l}\text { Wine D } \\
(\mathrm{mM})\end{array}$ & $\begin{array}{l}\text { Wine E } \\
(\mathrm{mM})\end{array}$ \\
\hline Putrescine & & 1.717 & 1.842 & 0.754 & 1.417 & 1.769 \\
\hline $\begin{array}{l}\text { Cadaver- } \\
\text { ine }\end{array}$ & & 0.025 & 0.050 & 0.049 & 0.063 & 0.060 \\
\hline Tyramine & & 0.108 & 0.375 & 0 & 0.406 & 0.623 \\
\hline $\begin{array}{l}\text { Phenyle- } \\
\text { thylamine }\end{array}$ & & 0.072 & 0.418 & 0.452 & 0.112 & 0.350 \\
\hline $\begin{array}{l}\text { Trypta- } \\
\text { mine }\end{array}$ & & 0 & 0 & 0 & 0 & 0 \\
\hline Histamine & & 0.39 & 0.742 & 0.175 & 0.416 & 0.494 \\
\hline
\end{tabular}

Of all the amines analysed, tyramine has a similar structure to histamine, and reaches higher values in 339 wines D and E, so it is likely to be producing a cross-reaction effect. In order to test this hypothesis, we 340 have run the test with standard solutions of histamine $(\mathrm{H})$ and tyramine $(\mathrm{T})$. In one case, we have used 2.5 $341 \mu \mathrm{g}$ of histamine while in the other we have also added $6.5 \mu \mathrm{g}$ of tyramine. This leads to tests with 0.22 342 and $0.69 \mathrm{mM}$ concentration of BAs. These tests were performed with iron oxide NPs as labels and evalu343 ated with the inductive sensor. The results are shown in Table 3 together with the "apparent histamine 344 amount," that is obtained applying the calibration parameters given in Figure (4). It can be concluded that 345 the presence of tyramine interferes at the test, which displays lower magnetic signals and give rise to a 346 value of histamine 27\% larger than the nominal one. Another parameter that can be affecting these results 347 is the different flowing velocity of the samples due to the matrix composition and viscosity. Although 348 further research is needed to improve the reliability of the test, the results of LFIA are a proof of the ca349 pability of the system not only to detect, but also to quantify histamine in red wine in the range of interest 350 for wineries and sensitive consumers.

351 Table 3 Cross reactivity study. The letters $\mathrm{H}$ and $\mathrm{T}$ stand for histamine and tyramine, respectively.

\begin{tabular}{cccc}
\hline BAs & $\begin{array}{c}\text { Concentration of BAs } \\
(\mathrm{mM})\end{array}$ & $\begin{array}{c}\text { Signal by inductive } \\
\text { measurements } \\
(\mathrm{mm} \cdot \mathrm{mV})\end{array}$ & $\begin{array}{c}\text { Apparent concentration of } \\
\text { histamine } \\
(\mathrm{mg} / \mathrm{L}) /(\mathrm{mM})\end{array}$ \\
\hline $\mathrm{H}$ & 0.22 & 1.5 & $26 / 0.23$ \\
$\mathrm{H}+\mathrm{T}$ & 0.69 & 1.3 & $33 / 0.28$ \\
\hline
\end{tabular}




\section{4. Conclusions}

354 A biosensor for histamine quantification in red wines has been developed based on the combination 355 of magnetic competitive lateral flow immunoassay strips and an inductive sensor to perform the reading 356 out. The labels are superparamagnetic iron oxide nanoparticles $10 \mathrm{~nm}$ in size with a double lipidic layer 357 as coating that enables their functionalization. The magnetic perturbation of the NPs is detected by the 358 inductive sensor as an increase of its impedance proportional to the number of NPs in the test line, which 359 is in turn proportional to the number of anti-histamine antibodies. The system has been calibrated with 360 histamine standard solutions. To validate the new method, the competitive immunoassay has been done 361 also with traditional gold NPs and evaluated, both with gold and magnetite, with a commercial reflectance 362 reader. The combination of magnetic particles and inductive reader gave the best calibration correlation 363 factor and LOD, besides the well-known magnetic pre-concentration potential.

364 Finally, the system was tested for reliability and validity with five real red wine samples correspond365 ing to different stages during vinification and the final consumption state. In this case, the magnetic parti366 cles proved a new advantage compared to colloidal gold, which is a better flow of the wine sample along 367 the paper resulting in a cleaner strip. In addition, the magnetic inductive signal does not depend on the 368 dyeing of the paper, which is a complication for gold labels whose reading relies on an optical signal.

369 The measurements were cross-checked by UHPLC, leading to the finding that in two of the wine 370 samples they can be overestimated in about $30 \%$, probably due to cross reactivity with tyramine. Despite 371 this, the conclusion is that the analytical method based on magnetic LFIA is very promising for point-of372 use determination of histamine. Keeping the advantages of simplicity, rapidity and low cost of traditional

373 LFIA, the magnetic character of the labels and their detection principle provide additional advantages like 374 the avoidance of sample pre-treatment for matrix removal, possibility of magnetic pre-concentration for 375 low concentration samples, improved calibration and LOD.

\section{5. Acknowledgements}

378 Wine samples were kindly provided by Juan M. Redondo from DOP Vino de Cangas. The authors 379 acknowledge the technical assistance of Begoña Redruello (IPLA) in the chromatographic analysis in 380 wine samples. This work was supported by the Spanish Ministry of Economy and Competitiveness under 381 projects MAT2017-84959-C2-1-R, MAT2016-81955-REDT and AGL2016-78708-R, the Council of 382 Gijón-IUTA under grant SV-18-GIJON-1-27, and the Principality of Asturias under project 383 IDI/2018/000185.

\section{6. Conflict of interest}

385 The authors declare no conflict of interest.

\section{7. References}

387 1. Ordóñez JL, Troncoso AM, García-Parrilla MDC, Callejón RM. Recent trends in the determination 388 of biogenic amines in fermented beverages - A review. Analytica Chimica Acta. 2016;939:10-25. 
2. Daniel ML, MaCruz M, Victor L, Miguel AA, María F. Biogenic Amines in Dairy Products. Critical Reviews in Food Science and Nutrition.51(7):691-703.

391 3. Ladero V, Calles-Enriquez M, Fernandez M, A. Alvarez M. Toxicological Effects of Dietary 392 Biogenic Amines. Current Nutrition \& Food Science. 2010;6(2):145-56.

393 4. Bodmer S, Imark C, Kneubühl M. Biogenic amines in foods: Histamine and food processing. 394 Inflammation Research. 1999;48(6):296-300.

395 5. FDA. Fish and Fishery Products Hazards and Controls Guidance, Fourth Edition, Chapter 7. April $3962011 ; 113$.

397 6. EU Directive, Regulation (EC) No 1441/2007 of 5 December 2007. Official Journal of European 398 Union. 2007.

399 7. Bauza T, Blaise A, Daumas F, Cabanis JC. Determination of biogenic amines and their precursor 400 amino acids in wines of the Vallée du Rhône by high-performance liquid chromatography with 401 precolumn derivatization and fluorimetric detection. Journal of Chromatography A. 1995;707(2):373-9.

402 8. Landete JM, Ferrer S, Polo L, Pardo I. Biogenic Amines in Wines from Three Spanish Regions. 403 Journal of Agricultural and Food Chemistry. 2005;53(4):1119-24.

404 9. Konakovsky V, Focke M, Hoffmann-Sommergruber K, Schmid R, Scheiner O, Moser P, et al. 405 Levels of histamine and other biogenic amines in high-quality red wines. Food Additives \& 406 Contaminants: Part A. 2011;28(4):408-16.

407 10. Caruso M, Fiore C, Contursi M, Salzano G, Paparella A, Romano P. Formation of biogenic amines 408 as criteria for the selection of wine yeasts. World Journal of Microbiology and Biotechnology. 409 2002;18(2):159-63.

410 11. Goñi DT, Azpilicueta CA. Influence of Yeast Strain on Biogenic Amines Content in Wines: 411 Relationship with the Utilization of Amino Acids during Fermentation. American Journal of Enology and 412 Viticulture. 2001;52(3):185-90.

413 12. Lonvaud-Funel A. Biogenic amines in wines: role of lactic acid bacteria. FEMS Microbiology 414 Letters. 2001;199(1):9-13.

415 13. Iranzo JM, Ferrer S, Pardo I. Which lactic acid bacteria are responsible for histamine production in 416 wine? J Appl Microbiol2005. 580-6 p.

417 14. Hernández-Orte P, Lapeña AC, Peña-Gallego A, Astrain J, Baron C, Pardo I, et al. Biogenic amine 418 determination in wine fermented in oak barrels: Factors affecting formation. Food Research International. 419 2008;41(7):697-706.

420 15. Peña-Gallego A, Hernández-Orte P, Cacho J, Ferreira V. High-Performance Liquid Chromatography 421 Analysis of Amines in Must and Wine: A Review. Food Reviews International. 2012;28(1):71-96.

422 16. García-Villar N, Hernández-Cassou S, Saurina J. Determination of biogenic amines in wines by pre423 column derivatization and high-performance liquid chromatography coupled to mass spectrometry.

424 Journal of Chromatography A. 2009;1216(36):6387-93.

425 17. Cunha SC, Faria MA, Fernandes JO. Gas Chromatography-Mass Spectrometry Assessment of 426 Amines in Port Wine and Grape Juice after Fast Chloroformate Extraction/Derivatization. Journal of 427 Agricultural and Food Chemistry. 2011;59(16):8742-53.

428 18. Daniel D, Santos V, Tadeu Rajh Vidal D, do Lago C. Determination of biogenic amines in beer and 429 wine by capillary electrophoresis-tandem mass spectrometry 2015.

430 19. Kivirand K, Rinken T. Biosensors for Biogenic Amines: The Present State of Art Mini-Review. 431 Analytical Letters. 2011;44(17):2821-33.

432 20. Basozabal I, Guerreiro A, Gomez-Caballero A, Aranzazu Goicolea M, Barrio RJ. Direct 433 potentiometric quantification of histamine using solid-phase imprinted nanoparticles as recognition 434 elements. Biosensors and Bioelectronics. 2014;58:138-44.

435 21. Henao-Escobar W, del Torno-de Román L, Domínguez-Renedo O, Alonso-Lomillo MA, Arcos436 Martínez MJ. Dual enzymatic biosensor for simultaneous amperometric determination of histamine and 437 putrescine. Food Chemistry. 2016;190:818-23. 
22. Marcobal A, Polo MC, Martín-Álvarez PJ, Moreno-Arribas MV. Biogenic amine content of red Spanish wines: comparison of a direct ELISA and an HPLC method for the determination of histamine in wines. Food Research International. 2005;38(4):387-94.

23. Hernández-Cassou S, Saurina J. Determination of Histamine in Wine Samples by Flow-Injection Analysis and Multivariate Calibration. Analytical Letters. 2013;46(11):1758-68.

24. T. Surya BS, V. Alamelu, A. Priyatharshini, U. Arisekar and S. Sundhar. Rapid Methods for Histamine Detection in Fishery Products. International Journal of Current Microbiology and Applied Sciences 2019;8.

25. Mak WC, Beni V, Turner APF. Lateral-flow technology: From visual to instrumental. TrAC Trends in Analytical Chemistry. 2016;79:297-305.

26. Wang D-B, Tian B, Zhang Z-P, Deng J-Y, Cui Z-Q, Yang R-F, et al. Rapid detection of Bacillus anthracis spores using a super-paramagnetic lateral-flow immunological detectionsystem. Biosensors and Bioelectronics. 2013;42:661-7.

27. Wang D-B, Tian B, Zhang Z-P, Wang X-Y, Fleming J, Bi L-J, et al. Detection of Bacillus anthracis spores by super-paramagnetic lateral-flow immunoassays based on "Road Closure". Biosensors and Bioelectronics. 2015;67:608-14.

28. Wang Y, Xu H, Wei M, Gu H, Xu Q, Zhu W. Study of superparamagnetic nanoparticles as labels in the quantitative lateral flow immunoassay. Materials Science and Engineering: C. 2009;29(3):714-8.

29. Zheng C, Wang X, Lu Y, Liu Y. Rapid detection of fish major allergen parvalbumin using superparamagnetic nanoparticle-based lateral flow immunoassay. Food Control. 2012;26(2):446-52.

30. Lago-Cachón D, Rivas M, Martínez-García JC, García JA. Cu impedance-based detection of superparamagnetic nanoparticles. Nanotechnology. 2013;24(24):245501.

31. Rivas M, Lago-Cachón D, Martínez-García JC, García JA, Calleja AJ. Eddy-current sensing of superparamagnetic nanoparticles with spiral-like copper circuits. Sensors and Actuators A: Physical. 2014;216:123-7.

32. Lago-Cachón D, Oliveira-Rodríguez M, Rivas M, Blanco-López MC, Martínez-García JC, Moyano A, et al. Scanning Magneto-Inductive Sensor for Quantitative Assay of Prostate-Specific Antigen. IEEE Magnetics Letters. 2017;8:1-5.

33. Bica D, Vékás L, Avdeev MV, Marinică O, Socoliuc V, Bălăsoiu M, et al. Sterically stabilized water based magnetic fluids: Synthesis, structure and properties. Journal of Magnetism and Magnetic Materials. 2007;311(1):17-21.

34. Redruello B, Ladero V, del Rio B, Fernández M, Martín M, Alvarez M. A UHPLC method for the simultaneous analysis of biogenic amines, amino acids and ammonium ions in beer. Food Chemistry. 2016;217:117-24.

35. Rodbard D. Statistical Quality Control and Routine Data Processing for Radioimmunoassays and Immunoradiometric Assays. Clinical Chemistry. 1974;20(10):1255.

36. Aguilar-Arteaga K, Rodriguez JA, Barrado E. Magnetic solids in analytical chemistry: A review. Analytica Chimica Acta. 2010;674(2):157-65.

37. Hayashi Y, Matsuda R, Maitani T, Imai K, Nishimura W, Ito K, et al. Precision, Limit of Detection and Range of Quantitation in Competitive ELISA. Analytical chemistry. 2004;76(5):1295-301. 


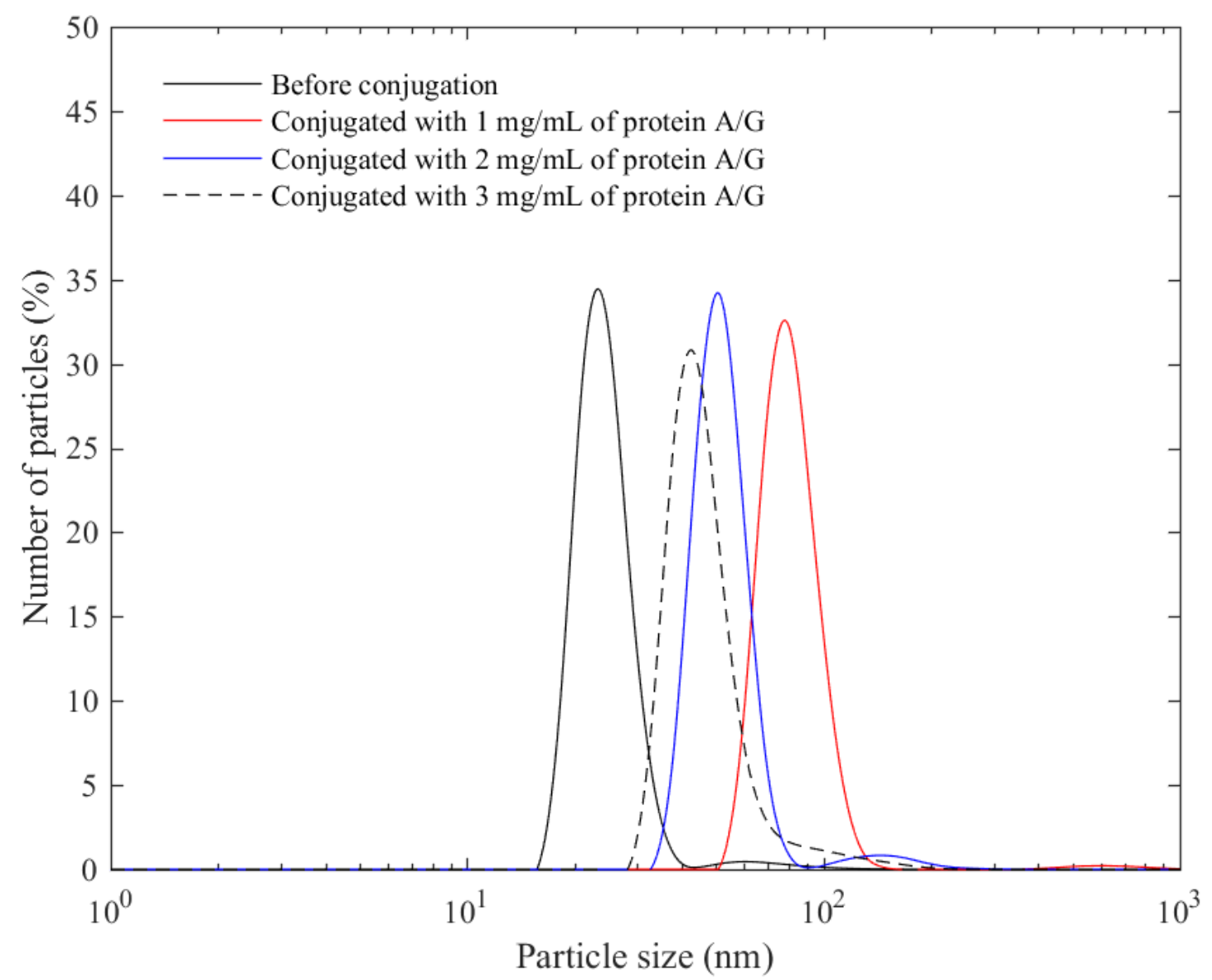

Figure 1. Hydrodynamic size distribution profiles of superparamagnetic iron oxide nanoparticles before (solid black line) and after conjugation with concentrations of $1 \mathrm{mg} / \mathrm{mL}$ (red), $2 \mathrm{mg} / \mathrm{mL}$ (blue) and $3 \mathrm{mg} / \mathrm{mL}$ (dashed) of protein $\mathrm{A} / \mathrm{G}$. 


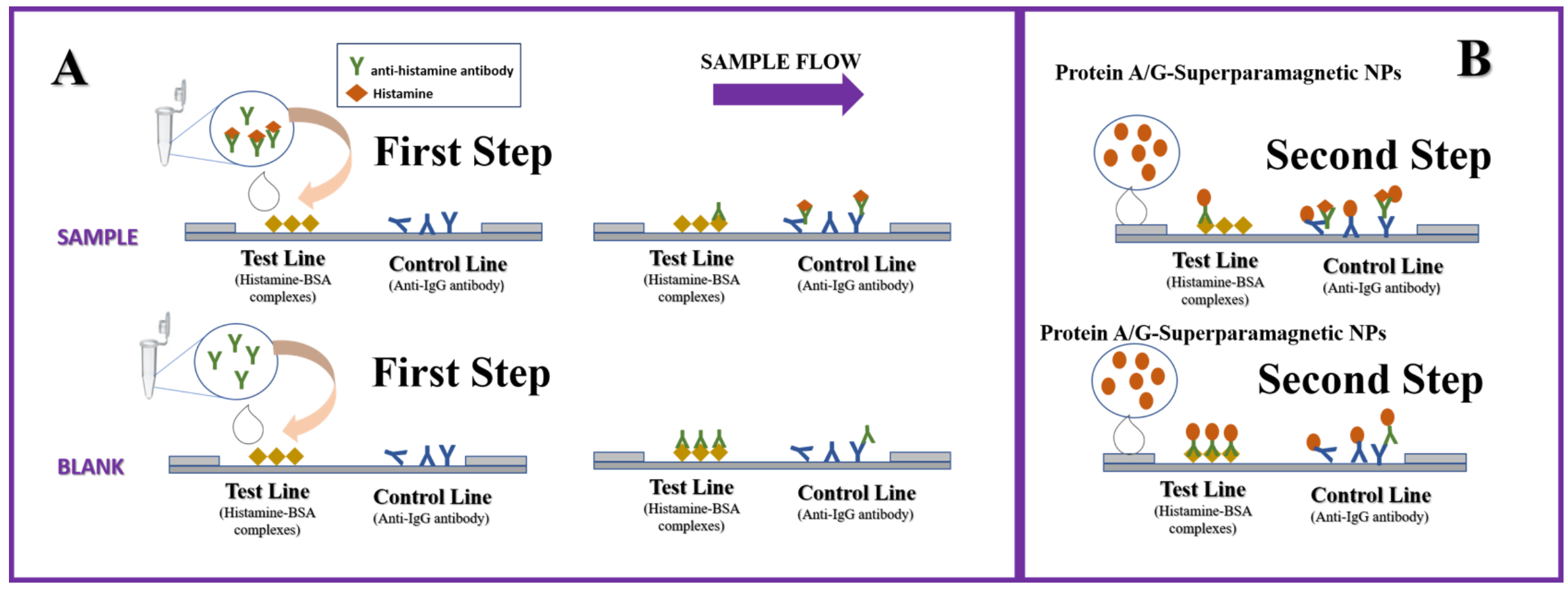

Figure 2. Schematic illustration of the competitive LFIA. (A) First step: immobilization of the anti-histamine antibodies. (B) Second step: colour development. 


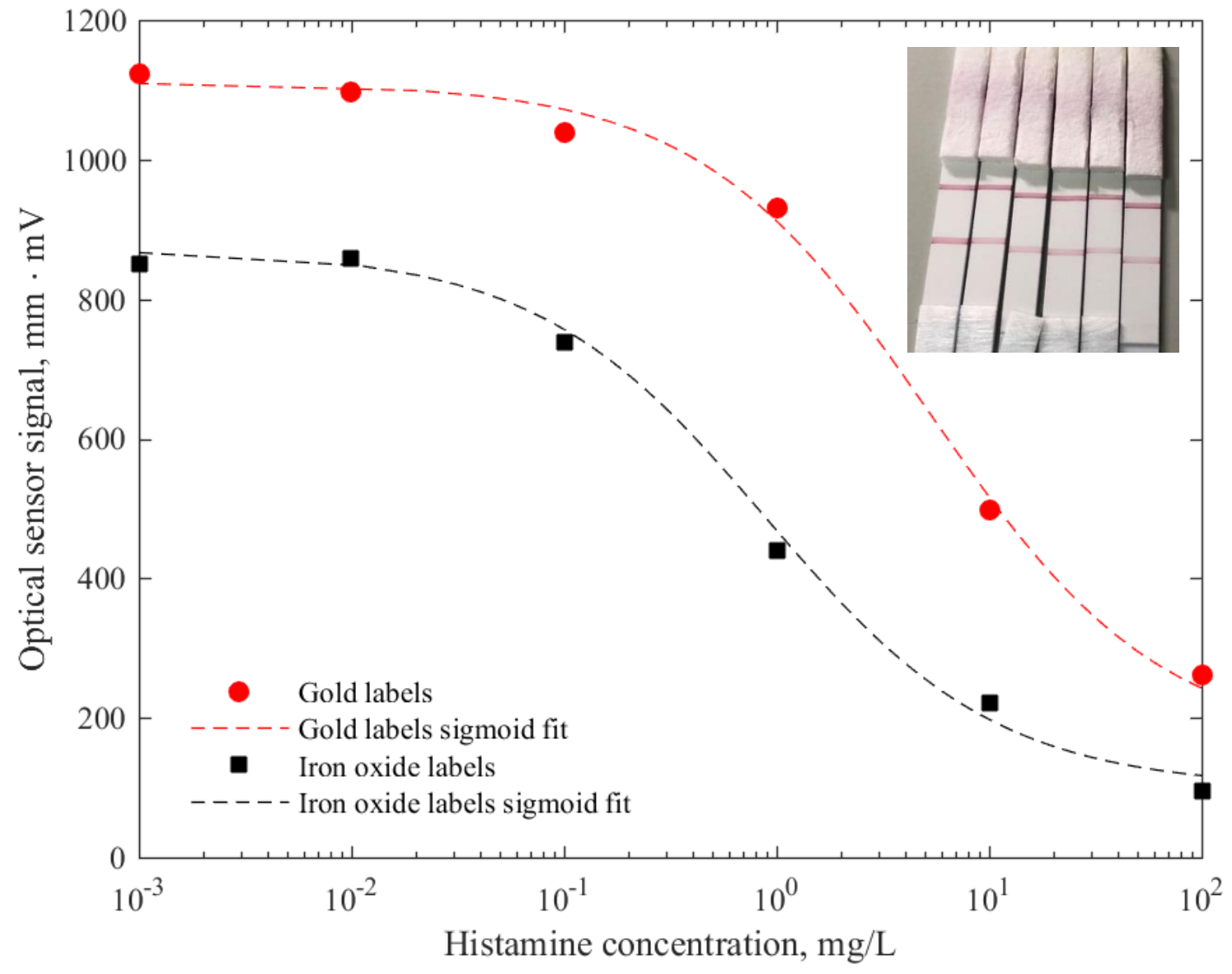

Figure 3. Quantification of LFIAs by the optical reader using gold (red) and iron oxide (black) NPs. The lines plotted to guide the eye are four-parameter sigmoid curves. Inset: One of the series of standard samples used to obtain the red curve, with the control line on top and the test line below. 


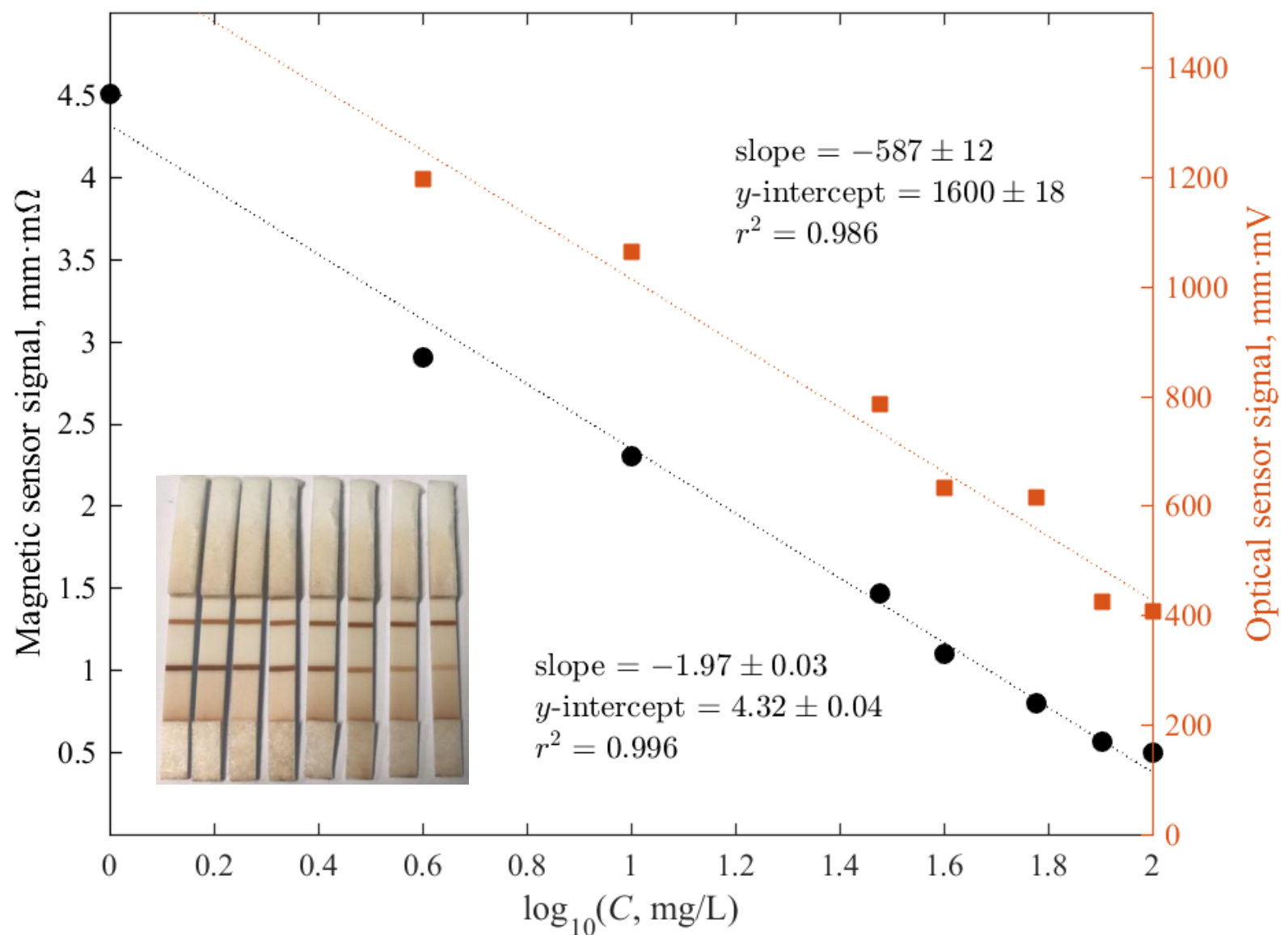

Figure 4. Inductive (left axis) and optical (right axis) signals of the magnetic LFIA as a function of the concentration of histamine. Least-squares linear regression curves are plotted as dotted lines. Inset: One of the series of standard samples used to obtain the plotted lines. The control line is on top and the test line below. 


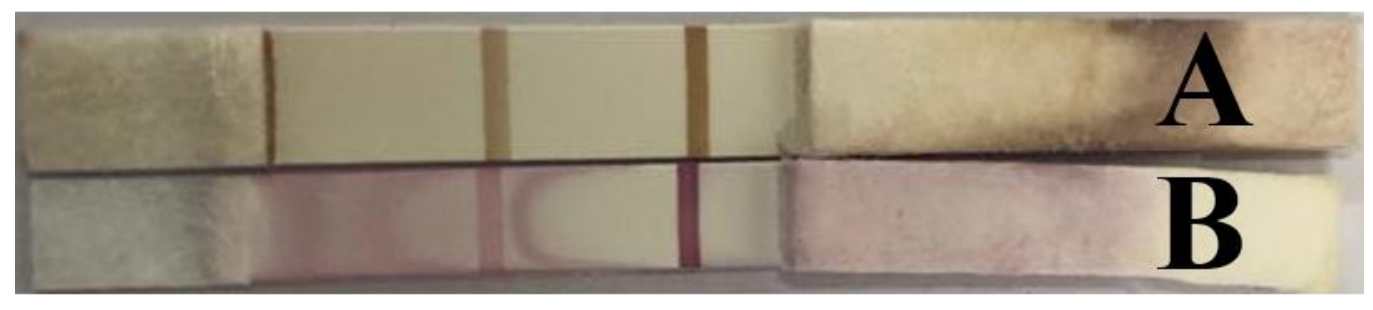

Figure 5. LFIAs run with red wine samples using (A) superparamagnetic nanoparticles and (B) colloidal gold as reporters. 